\title{
Exploring motivational strategies in higher education: Student and instructor perceptions
}

\author{
Zeynep Erdil-Moody * (D), Amy S. Thompson ${ }^{b}$ \\ a University of South Florida, Department of World Languages, Tampa, 33620, USA \\ ${ }^{b}$ West Virginia University, Dept. of World Languages, Literatures, \& Linguistics, Morgantown, 26506, USA
}

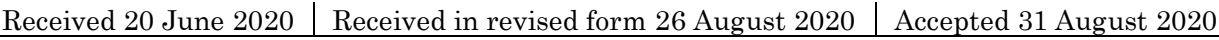

APA Citation:

Erdil-Moody, Z., \& Thompson, A. S. (2020). Exploring motivational strategies in higher education: Student and instructor preceptions. Eurasian Journal of Applied Linguistics, 6(3), 387-413.

Doi: 10.32601/ejal.834670

\begin{abstract}
This study offers cross-cultural validity of motivational strategies, as well as reliability and validity measures of an adapted questionnaire in a new context. Foreign/second language (L2) learning motivation has long been demonstrated to have a substantial impact on second language acquisition; L2 teachers play a major role in learner motivation with their use of motivational strategies in classes (Dörnyei, 2001; Dörnyei \& Kubanyiova, 2014). Motivational strategies vary in their effectiveness and appropriateness in different EFL contexts (e.g., Dörnyei, 2001; Guilloteaux \& Dörnyei, 2008). There is little research, however, in combining the theory and practice in motivation research; in other words, there are few studies that examine motivational strategy research in conjunction with the L2 Motivational Self System (L2MSS). To fill this gap, the current study examined college EFL instructors' motivational teaching practices, informed by the ideal L2 self guide in Turkey, from both instructors and students' perspectives. Quantitative data were collected via a motivational strategies questionnaire that was created and validated specifically for this study - Teachers' Use of Motivational Strategies Scale (TUMSS). Descriptive statistics, independent samples $t$-tests, and an exploratory factor analysis (EFA) were conducted to analyze the data $(N=454)$. Results indicated that instructors frequently used a variety of motivation-enhancing strategies; group comparisons of perceptions and EFA results via the three latent variables raised some important issues; independent samples t-tests indicated a statistically significant group difference for the strategies in Factor 3, those related to the ideal L2 self, while showing no difference for the other two factors. Pedagogical implementations are discussed.
\end{abstract}

(C) 2020 EJAL \& the Authors. Published by Eurasian Journal of Applied Linguistics (EJAL). This is an open-access article distributed under the terms and conditions of the Creative Commons Attribution license (CC BY-NC-ND) (http://creativecommons.org/licenses/by-nc-nd/4.0/).

Keywords: L2 Motivation; L2 motivational self system; motivational strategies; motivational teaching practice; exploratory factor analysis (EFA); Turkish EFL context; SPSS select case.

\section{Introduction}

In the field of Second Language Acquisition (SLA), foreign/second language (L2) motivation has long been one of the most investigated areas due to its profound impact

\footnotetext{
* Corresponding author.Tel.: +1-902-563-1315

E-mail address: zerdil@mail.usf.edu

http://dx.doi.org/10.32601/ejal.834670
} 
on L2 learning. Many L2 motivation theories and models have been offered for decades and examined in various English as a foreign language (EFL) contexts to better understand the multifaceted L2 motivation construct; yet, students' low motivation to pursue the long and generally laborious L2 learning process is still one of the biggest challenges teachers face in L2 classes. At times, a focus on theoretical perspectives has steered attention away from practical classroom strategies to enhance student motivation. Recently, however, more classroom-oriented research has focused on teachers' roles in how to increase learners' motivation (e.g., Kubanyiova, 2006; Moskosky, Alrabai, Paolini \& Ratcheva, 2013; Papi \& Abdollahzadeh, 2012). Keeping teachers' pedagogical practices in L2 classes as the focus of investigations, recent research guided by Dörnyei's (2001) Motivational Teaching Practice in the L2 Classroom (MTP) model has highlighted results indicating that the motivational strategies that teachers use in the L2 classroom have a strong positive impact on students' motivation (e.g., Dörnyei \& Kubanyiova, 2014; Guilloteaux \& Dörnyei, 2008; Henry, Korp, Sundqvist, \& Thorsen, 2018). With a focus on the motivational teaching strategies, it is noteworthy that this model typically does not examine teachers' strategy usage within the latest domains of L2 motivation research. Dörnyei's (2005; 2009) L2 Motivational Self System Theory (L2MSS) has predominated motivation research in certain contexts since 2009, and its validity has been denoted across various L2 contexts; however, investigations of L2 teacher strategies have hardly included those grounded in this theory (Dörnyei \& Hadfield, 2014). The current study is unique in that it aims to connect the theoretical L2 motivation framework (L2MSS) with the practice model (MTP), taking these two models as the underlying theoretical frameworks for investigating L2 teachers' motivational strategy use. Another key issue this study addresses is the perceptional differences between teachers and students in terms of teachers' strategy use in class, which is discussed in more detail in the strategy section below.

\subsection{Theoretical background: L2 motivational self system}

L2 motivation research has been guided by many theories for decades aiming to provide a comprehensive understanding of such a multifaceted phenomenon. Most recently, Dörnyei proposed a tripartite L2 motivation theory: the L2 Motivational Self System (L2MSS), comprised of ideal L2 self, ought-to L2 self, and L2 learning experience (Dörnyei, 2005; 2009). The reconceptualization of the two future self-guides draws upon the integrative and instrumental motivation notions of the SocioEducational Model (Gardner, 1985) and three self-theories of motivation research: Possible Selves (Markus \& Nurius, 1986), Self-Discrepancy (Higgins, 1987), and SelfDetermination theory (Deci \& Ryan, 1985). The ideal L2 self construct represents all the wishes, aspirations, desires, goals, and motives that a person would like to have related to their target L2. Markus and Nurius' (1986) ideal self-guide suggests that the long-term goals and motives in one's repertoire of possible selves postulate certain selfrelevant incentives and direction to future behaviors, drawing a conceptual connection between cognition and motivation. Likewise, Higgins' (1987) self-discrepancy theory 
suggests that people are motivated to diminish the discrepancy between their actual selves - who they are now - and the self in their possible selves repertoire to which they relate; thus, they are motivated to attain the characteristics that their self-guides represent. Dörnyei (2005; 2009) suggests that highly motivated L2 learners are more committed and eager to minimize the discrepancy between their actual selves and ideal or ought-to L2 selves. Unlike the internal motivational drive of ideal L2 self, ought-to L2 self refers to L2-related responsibilities, duties, obligations, or professional status learners believe they ought to possess based on society or family's expectations (Dörnyei, 2005; 2009). Clearly, while the ideal L2 self has a promotion focus derived from the long-term L2-related goals learners want to achieve, the ought-to L2 self is driven by the external and instrumental motives that are not yet internalized. Other self concepts have augmented the L2MSS; for example, the anti-ought-to self (Thompson, 2017) is conceptualized as a self that positively responds to challenges or excelling at the unexpected. The third construct, L2 learning experience, is the least theorized. Dörnyei (2019) conceptualized it as motivated learning behavior, whereas Thompson (2017) conceptualized it as the complex relationship between language learners and their micro and macro contexts that help inform their self formation. Likewise, Begic and Mercer (2017) suggest it comprises learners' past and ongoing present experiences. As mentioned earlier, for the current study, L2MSS provided the theoretical background for the development of ideal L2 self enhancement strategies for the motivational teaching scale TUMSS, thereby modifying the unique well-established MTP model to offer a more comprehensive sound measurement scale for L2 practitioners and researchers to evaluate motivational strategy use in L2 classes.

\subsection{Motivational strategies and motivational teaching practice in the L2 classroom}

To date, Dörnyei's (2001) Motivational Teaching Practice in the L2 Classroom (MTP) model provides the most comprehensive taxonomy of motivational strategies, offering 102 motivational techniques that can be used in the L2 classroom. Motivational strategies are techniques that teachers use to foster learners' desire to achieve their L2-related goals and to help them maintain their persistence and enthusiasm for L2 learning. These strategies need to be consciously exerted in a systematic and consistent way to have the enduring strong positive impact on learner motivation (Dörnyei, 2001). Dörnyei categorizes these strategies under four major consecutive stages, which were inspired by Dörnyei and Otto's (1998) process model of L2 motivation: creating the basic motivational conditions, generating initial motivation, maintaining and protecting motivation, and encouraging positive retrospective self-evaluation. Within these four stages, he compiles 20 macro-strategies representing major characteristics of motivational teaching practice, under each of which he lists several strategies to be used in the language classroom to generate and maintain motivation. Starting with some prevalent effective teaching techniques and teachers' appropriate behaviors to create a supportive, stress-free, and motivating atmosphere in the classroom as the preconditions to initiate motivation, stages further strengthen learner motivation with 
a deeper and enduring effect on their beliefs, linguistic confidence and goal-oriented behaviors (Dörnyei, 2001, p. 29, for the full model).

Since Dörnyei's (2001) MTP model, research in various L2 contexts has illustrated the significant impact that motivational strategies used by EFL teachers have on learner motivation (e.g.; in United Kingdom, Busse \& Walter, 2013; in Taiwan, Cheng \& Dörnyei, 2007; in Saudi Arabia, Alrabai, 2016; Moskovsky et al., 2013; in South Korea, Guilloteaux \& Dörnyei, 2008; in England and Hong Kong, Magid \& Chan, 2012; in Iran, Papi \& Abdollahzadeh, 2012). With these strategies, L2 teachers have the power to make a real difference in promoting learner motivation; yet, researchers have also argued that culture-specific and institutional variables such as the importance attached to learning the target L2 in the society, L2-related ideologies, institutional goals, and teachers' and learners' approaches to teaching/learning a language are likely to render some strategies less useful, while others particularly effective (e.g.; Cheng \& Dörnyei, 2007). For instance, some strategies were argued to likely transcend certain contextual variables, allowing them to be universally effective motivational strategies such as displaying appropriate motivating teacher behaviors, setting a personal example by showing a strong interest in L2 learning, presenting tasks properly, promoting learners' self confidence, including in the activity design elements of interest, creativity, and curiosity, and creating a pleasant and safe classroom environment (Cheng \& Dörnyei, 2007; Dörnyei \& Csizér, 1998; Guilloteaux \& Dörnyei, 2008). Unlike these, some strategies were found to be effective only in certain contexts, such as establishing relevance between the course content and students' lives outside the classroom (Alrabai, 2016; Guilloteaux \& Dörnyei, 2008; Moskovsky et al., 2013), increasing students' awareness of their progress (Busse \& Walter, 2013), bringing in humor and fun into the L2 classroom (Moskovksy et al., 2013), and vision building strategies (Arnold, Puchta, \& Rinvolucri, 2007; Magid \& Chan, 2012; Mackay, 2019). Strategies like these require some mitigation if used. Finally, some strategies were reported as the least used strategies across cultures such as promoting learner autonomy, familiarizing learners with L2 culture, inviting senior students to share their English learning experience, and making learning tasks stimulating (e.g.; Cheng \& Dörnyei, 2007). Hadfield and Dörnyei (2014) highlight increasing awareness of intercultural communication and Dörnyei and Kubanyiova (2014) emphasize enhancing ideal L2 self vision as effective motivational strategies. All these strategies mentioned above were also included in the TUMSS questionnaire for the current study in the context of Turkey to first examine the crosscultural validity of the TUMS scale with the new ideal L2 self enhancement strategy section and secondly to see which strategies are preferred by the EFL instructors in this specific context, aiming to contribute to the above-reported relevant literature.

In addition to the gap between the existing MTP model and the L2MSS theory, the second concern that this study addresses is whether motivational strategies used by instructors correspond to the expectations of students. Research shows that teachers and students perceive instructional practices differently (Bernaus \& Gardner, 2008). For example, while some studies found a disparity between student and teacher perceptions of instructional strategies in the L2 classroom (e.g.; Bernaus \& Gardner, 
2008; Schulz, 2001), others indicated how the two groups perceive classroom environments differently (e.g.; Raviv, Raviv, \& Reisel, 1990). Researchers argue that for strategies to be effective in increasing student motivation, they should be perceived by both groups as important and frequently employed in class (Bernaus \& Gardner, 2008). Similarly, Safdari (2018) found a weak but significant correlation between the motivational strategies students deemed as important and those they perceived as frequently used in class. From this finding, we can infer that students are likely to perceive a given strategy frequently used in L2 class when they perceive it important for their language learning. Hence, we believe research in different EFL contexts regarding students and instructors' perceptions of frequency of motivational strategies can inform pedagogical practices and offer implications for motivational teaching. There appears to be little research, however, that has examined both teachers and students' perceptions of motivational strategy use in language classes in conjunction with examining the L2MSS framework in the same context.

\subsection{Research gap and purpose of the study}

The original motivational teaching taxonomy obviously does not include any strategies directly targeting learners' ideal L2 self as it precedes the L2MSS. However, considering the plethora of research indicating the importance of the ideal L2 self as the strongest predictor of learner motivation, it seems pedagogically appropriate to include strategies to enhance learners' vision of their ideal L2 self in teachers' motivational strategy use. Dörnyei (2009) highlights the importance of a) awareness raising, b) increasing learners' mindfulness of possible L2-related selves that they could/would like to become in the future, c) presenting powerful role models, and d) guided vision-building tasks to help learners form an ideal L2 self. To date, there have been only few studies exploring the impact of vision-building strategies on learner motivation (e.g.; Magid \& Chan, 2012; Mackay, 2019) and a few books about vision building in the L2 classroom (Arnold, Puchta, \& Rinvolucri, 2007; Dörnyei \& Kubanyiova, 2014; Hadfield \& Dörnyei, 2014). However, as to our knowledge, there has been no established motivational strategies scale that is informed by the L2MSS (Dörnyei, 2005; 2009) to measure college L2 instructors' motivational strategy use.

To fill the gap, ideal L2 self enhancement strategies were consciously integrated into the motivational strategy questionnaire, TUMSS. The overarching goal of the current study is to connect the theory (L2MSS - Dörnyei, 2005; 2009) with practice (MTP Dörnyei, 2001) by integrating vision-building strategies in the motivational strategies questionnaire, TUMSS (Erdil, 2016). To achieve this goal, we started with two objectives that also formulated our research questions. The first objective of this study is to examine whether L2 instructors use any motivation-enhancing strategies in their classes and if they do, which strategies they use and at what frequency. The second objective is to compare instructors' and their students' perceptions of the frequency at which instructors use motivational strategies in university-level EFL classes to examine if there is a statistically significant difference between their perceptions. We hypothesized that the motivational strategies teachers think that they regularly 
perform might not be those that the students perceive are regularly performed. Considering previous research on the positive correlation between students' perceptions of how frequently strategies are used in class and their perceived importance, we aim to offer pedagogical insights via our analysis of both perspectives. Additionally, we believe our data on university L2 instructors' motivational strategy use in the understudied EFL context of Turkey will provide cross-cultural validity of motivational strategies in this specific context. This study might also contribute to L2 teacher education by providing insights into designing a motivational teaching program for preservice EFL teachers or professional development for in-service teachers. The two questions that guided this study are as follows:

1. What is the reported motivational strategy use of EFL instructors?

2. Are there significant differences between EFL instructors' and their students' perceptions of instructors' use of motivational strategies?

\section{Method}

This study reports on the first phase of a larger project presenting the results of a quantitative questionnaire survey of English for Academic Purposes (EAP) instructors' use of motivational strategies at a large state university in the Turkish EFL context.

\subsection{Research setting}

The research setting is a foreign language department of a large English-medium state university in Turkey. This co-educational research university hosts about 26,500 students from around the country. The department offers numerous elective language courses and the required EAP courses to matriculated university students. The EAP courses are available every semester and focus on academic language skills, writing research papers, synthesizing literature, and performing academic presentations. They are all theme-based with a focus on learner-centered teaching and organized into modules aiming to develop students' critical thinking/reading skills as well as academic English and writing skills. English-medium instruction at the university places a critical role for students' motivation to learn English in order for them to achieve their academic goals. However, low student motivation has been a major challenge in these EAP classes. Thus, learner and teacher motivation are foregrounded in this course to achieve expected high academic outcomes.

\subsection{Participants and sampling procedures}

A sample of 454 university EAP/EFL instructors and their students at a state university in Turkey participated in this study - 32 instructors and their 422 students. Instructor participants, whose ages ranged from 24 to 60 , all hold foreign language/English language teaching degrees, mostly at the graduate level.

Students were all freshmen from a wide variety of disciplines taking this compulsory EAP course four hours a week in their second semester in the program. Their ages 
ranged from 19 to 30 . As a top-ranked university, the students are those who performed well in high school and were successful on the National University Entrance Examination. Unless they have a TOEFL or IELTS exemption or pass the university English proficiency test, students must first attend a semester or yearlong intensive English program to prepare them for the English medium instruction of the university. As these student participants were almost ready for university, they were at high intermediate to advanced levels of English proficiency. They were recruited from different sections of the same required EAP course to achieve consistent data.

\subsection{Instrument - Teachers' use of motivational strategies scale: TUMSS}

The current study used the Teachers' Use of Motivational Strategies Scale (TUMSS) that the first author developed and designed (Erdil, 2016). Dörnyei's (2001) Motivational Teaching Practice in the L2 Classroom model (MTP) and L2MSS (2005; 2009) provided the theoretical background for TUMSS' design. The questionnaire has both a student and teacher version. In other words, student version is the same questionnaire as teachers' but reworded from students' perspective and it was administered in both English and Turkish so as to avoid any misinterpretations of the questions (see Appendix A for both questionnaires). There are 25, 6-point Likert scale items in the questionnaire: 6 (almost always), 5 (often), 4 (generally), 3 (sometimes), 2 (occasionally) and 1 (almost never).

TUMSS items reflect all four stages of the process-oriented MTP model, as several macro and micro strategies from each stage were adapted to provide a wide range of motivational strategy measures. Additionally, to address the above-mentioned shortcoming of the model, new strategies were added based on the L2MSS theory, specifically those related to the ideal L2 self and learning experience, with a focus on the ideal self. TUMSS is an evidence-based questionnaire, as it aligns with the previous research in terms of its scope covering similar strategies. The inclusion criteria considered during the design of the instrument were as follows:

1. Strategies that can be used to enhance learners' ideal L2 self, mental image of themselves as proficient L2 speakers - integration of the L2MSS framework

2. Strategies that can be used in class to foster students' overall L2 learning experience - integration of the L2MSS frame

3. An eclectic yet concise instrument to measure L2 teachers' motivational strategy use that can still reflect a wide range of motives to learn an L2

4. Strategies reported as most and least commonly used by previous research in different EFL contexts in order to provide cross-cultural validity of motivational strategies

5. Appropriate strategies for university-level EFL learners in this specific context

These criteria were helpful while choosing which strategies to include in TUMSS in that strategies that did not fall within these parameters were excluded. For instance, 
MTP model's macro strategy groups for using grades in a motivating manner, developing a relationship with students' parents, explicitly formulated group norms and their consistent observations, as well as micro strategies such as putting group rules and the consequences for violating them on display, preventing rigid seating plans, or encouraging the learners to personalize the classroom environment were not considered for TUMSS based on the fifth criterion. For the first two criteria based on the L2MSS, new strategies to enhance learners' ideal L2 self and L2 learning experience were developed; these were teaching self-motivating strategies by strengthening students' visual image of themselves with high English proficiency (item 21) and emphasizing the importance of intercultural communication (item 22). Likewise, other strategies that were relevant to these two L2MSS constructs by increasing learners' awareness of the significance of learning the L2 and exposure to target L2 culture and community were also paraphrased/ edited and included in the questionnaire.

As suggested in Dörnyei and Taguchi (2010), TUMSS was piloted with a sample population in the same research setting to ensure its validity, appropriateness, and clarity of instructions in this context and revised accordingly before the questionnaire was finalized. Based on the feedback, a few items were simplified to facilitate students' comprehension and some were divided into separate items if they included multiple components, while others were adapted accordingly to address university students' maturity and cognitive levels. For instance, increasing learner satisfaction macro strategy with its three micro strategies (monitor student accomplishments and take the time to celebrate any victory, including tasks that allow for public display of students' skills) were replaced by more context- and age-appropriate strategy offering praise and constructive feedback for effort and/or achievement (item 15).

Other measures taken in the design process of TUMSS to collect more reliable and meaningful data involved keeping the questionnaire short to circumvent survey fatigue, avoiding personal questions, and emphasizing confidentiality and anonymity of the responses to eliminate the social desirability bias (Erten, 2014; 2015).

\subsection{Data collection and analysis}

After the approval for the study was obtained from the university ethics board, the department chair's approval was received to both conduct the study at the research setting and to recruit instructors and students at the department to participate in the study. Next, 72 instructors in the department were sent an email to solicit participation three weeks before the semester started. The email included details, a brief summary and potential contributions of the study, as well as a link to SurveyMonkey for the questionnaire. Participation was on a voluntary basis and data were collected and recorded anonymously via the self-report questionnaire - Teachers' Use of Motivational Strategies Scale (TUMSS) - from the EFL student and instructor participants. Upon completing the teacher version of the motivational teaching questionnaire, instructors were asked to invite their students that they were teaching at the time of data collection 
to complete the paper-based student version of TUMSS at their own convenience. Data were analyzed using SPSS version 23.

Conducting a priori power analysis is fundamental to identify the number of participants one should include in a quantitative study in order to obtain the ideal power $(0.80)$ and effect size ( $f=0.40$ ) with Alpha at .05 (Larson-Hall, 2016; Plonsky \& Oswald, 2014). A power level of 0.80 , for instance, suggests that there is an $80 \%$ chance of identifying the effect if there is any (Larson-Hall, 2016). The priori power analysis, conducted on the G*Power program (http://www.gpower.hhu.de/), indicated 52 as the required sample size to obtain the power at 0.80 and the effect size at $f=0.40$, which is a large effect size. An important parameter, a large effect size allows researchers to interpret the size of the group difference based on the results even if they are not statistical (Larson-Hall, 2016). Cohen's $d$ guidelines were followed for the effect size.

To answer RQ1, descriptive statistics were run on the teacher version of the TUMSS data to examine the types of motivation-enhancing strategies university EFL instructors use and how frequently they use each strategy. A Cronbach's alpha reliability analysis was performed to examine the inter consistency of the questionnaire items. RQ2 was answered by using independent samples $t$-tests to examine the potential difference between the mean scores of the teacher and student participant groups. Descriptive statistics were also employed to have a visual representation of the student data to help answer RQ2. An exploratory factor analysis (EFA) was conducted before the $t$-tests to organize the data and explore the interrelationships of questionnaire items to identify patterned themes by reducing the variables to a more manageable number of latent variables called factors (Field, 2013). An exploratory, rather than confirmatory, factor analysis (EFA vs. CFA) was chosen for this data because the TUMMS questionnaire was designed for this study and was used in this context for the first time; thus, exploring factors that explain the interrelationships among scale items in this context was necessary to validate the questionnaire items; Confirmatory factor analyses are used to confirm the ability of a hypothesized factor model to fit an observed data set (Loewen \& Gönülal, 2015). Research highlights the importance of analyzing multi-scale questionnaire data via EFAs in diverse contexts for validation of factors to understand how data show variation in different foreign language contexts (e.g.; Field, 2013; Thompson \& Erdil-Moody, 2016; Thompson \& Lee, 2013; Thompson \& Sylvén, 2015). Therefore, an EFA was the appropriate choice to explore factors in the TUMSS data in this context because we did not have specific theoretical expectations about the nature or number of factors within our data. The reason for this was that there were no preceding studies examining motivational teaching practice guided by the L2MSS theory that could provide a theoretical and empirical rationale to predetermine factors. The Maximum likelihood extracting method with a direct oblimin (oblique) rotation were used for this analysis, as these are the preferred parameters for naturalistic data (i.e. data involving humans, (Conway \& Huffcutt, 2003; Field, 2013; Loewen \& Gönülal, 2015).

Before conducting the EFA, two preliminary analyses were done to determine if the data set was conducive to an EFA: sample size and Kaiser-Meyer-Olkin (KMO) value, 
both of which are critical for the reliability of the analysis. For sample size the recommended number is 10-15 participants per variable which corresponds to approximately 375 participants for our 25-item questionnaire data and for the KMO value the goal is above 0.5 (Field, 2013). The small sample size of the instructor group ( $n=32 ; C A=.81)$ and low KMO value at .40 in an initial EFA necessitated to conduct EFA on the combined data of both student and instructor groups, following Field's (2013) recommendation in the case of a small sample size. Furthermore, to examine a potential difference between groups to answer RQ2, both groups' data needed to be comparable; in other words, the same factor loadings needed to be used for further analyses. An EFA was first conducted with only the student data ( $n=422 ; 25$ items, $C A=.89)$ and then with the combined student and instructor data $(N=454 ; 25$ items, $C A=.90)$ to observe if factor loadings would alter as a result of data merge. Factor loadings were the same and the KMO value in both analyses was .93, indicating factor analysis could generate distinct and reliable factors (Field, 2013). The anti-image correlation matrix was examined and the values were above the bare minimum of .5.

\section{Results}

\subsection{RQ1: Reported motivational strategy use of EFL instructors}

To answer RQ1, instructor TUMSS data were analyzed via descriptive statistics (Table 1). Overall, instructors reported that they frequently use $72 \%$ (18 out of 25 ) of all the strategies in their classes. Strategies reported to be used generally ( $4=$ generally) and above were included in this percentage. Descriptive statistics demonstrated seven strategies with the highest mean scores, ranging from 5.03 to 5.38 in a 6 -point Likert scale $(5=$ often). Among all the motivational strategies, 'Promoting interaction and cooperation in classes' (item 9) has the highest frequency, 'Creating a friendly stressfree learning environment' (item 3) and 'Caring for student progress' (item 25) both have the second highest mean. The top seven strategies that were most frequently used, not surprisingly, were all related to teacher motivation to create an effective teaching and learning environment using motivational strategies and encouraging interaction among learners (e.g.; strategies 9, 3, 25, 15, 5,16, \& 13). On the other hand, the least used strategy was strategy 19 "Inviting senior students to talk to the class about their positive experiences" ( $M=1.09 ; S D=.78)$ while strategy 7 "Sharing positive views of influential public figures about language learning" $(M=2.84 ; S D=1.63)$ and strategy 21 "Strengthening students' visual image of themselves with high language proficiency in English" ( $M=3.09 ; S D=1.49$ ) were the second and third least used strategies, respectively. Strategies like these that aim to increase learner's L2-related desires to achieve an ideal image of themselves as highly proficient L2 speakers were rarely used in this context so were not yet a part of instructors' motivational teaching practice.

\subsection{RQ2: The Difference between instructors' and students' perceptions of instructors' use of motivational strategies - Descriptive Statistics}


The second research question investigated whether there was a statistically significant difference between instructors' and students' perceptions of instructors' use of motivational strategies. Table 1 below provides descriptive statistics of both groups side by side to have a better understanding of overall tendency across groups before discussing the $t$-test analyses.

Group means showed both similar and different tendencies across data sets. Very close to instructors' report on the frequent use of the $72 \%$ of all TUMSS strategies, students reported that their instructors used $68 \%$ of the strategies frequently in their classes (17 out of 25 ). Similarly, six strategies were reported to be used most frequently, ranging from 5.10 to 5.35 in a 6 -point Likert scale $(5=$ often) and eleven strategies to be generally ( $4=$ generally) used. It was observed that the same four strategies (strategies 3, 9, 15, and 16) had high mean scores above 5 in both groups' data sets, and the same two strategies were among the highest. There were also differences; for example, $64 \%$ of students' mean scores were lower than instructors' ( 16 out of 25 items, see strategies 10 and 21 as examples). It is also noteworthy that mean scores for some strategies in instructor data were above average frequency $(M=4.00-4.99)$ while the same items in the student data were below average $(M=3.00 ; 3=$ sometimes); see strategies 18 and 4 as examples. Using descriptive statistics, the student data demonstrated larger standard deviations, indicating more diversity in student responses compared to more consistent instructor responses. The significant group differences ( $t$-tests) are reported in section 3.4 below. After each item in Table 1, the factor numbers are listed, with N/A for the three items that did not load on any factors; Highest means over five are underlined in Table 1 for ease of interpretation. Table 2 has the items separated by factors based on the EFA results.

Table 1. Descriptive Statistics of all TUMSS - Instructor and Student Data $(N=454)$

\begin{tabular}{|c|c|c|c|c|}
\hline & \multicolumn{2}{|c|}{$\begin{array}{l}\text { Instructors } \\
(n=32)\end{array}$} & \multicolumn{2}{|c|}{$\begin{array}{l}\text { Students } \\
(n=422)\end{array}$} \\
\hline & Mean & $S D$ & Mean & $S D$ \\
\hline 1. Using ice breakers at the beginning of each class (F1) & 4.44 & 1.56 & 4.76 & 1.38 \\
\hline 2. Clearly stating lesson objectives at the beginning each class (F1) & 4.78 & 1.43 & $\underline{5.34}$ & 1.00 \\
\hline 3. Creating a friendly stress-free learning environment (F1) & $\underline{5.31}$ & .99 & $\underline{5.35}$ & 1.00 \\
\hline 4. Encouraging risk-taking in classes (N/A) & 4.30 & 1.24 & 3.86 & 1.56 \\
\hline 5. Giving a genuine meaningful purpose to students to work on activities (F1) & $\underline{5.22}$ & .75 & 4.86 & 1.20 \\
\hline 6. Establishing connections between course content and outside world (F1) & 4.81 & .93 & 4.44 & 1.42 \\
\hline $\begin{array}{l}\text { 7. Sharing positive views of influential public figures about language Learning } \\
\text { (F3) }\end{array}$ & 2.84 & 1.63 & 1.84 & .755 \\
\hline $\begin{array}{l}\text { 8. Emphasizing in class teacher's own personal interest in learning English } \\
\text { (F3) }\end{array}$ & 3.34 & 1.19 & 3.16 & 1.76 \\
\hline 9. Promoting interaction and cooperation in classes (F2) & $\underline{5.38}$ & .66 & $\underline{5.22}$ & 1.09 \\
\hline $\begin{array}{l}\text { 10. Promoting exposure to L2 cultural products to familiarize students with the } \\
\text { L2 }\end{array}$ & 3.59 & 1.36 & 1.78 & .765 \\
\hline
\end{tabular}




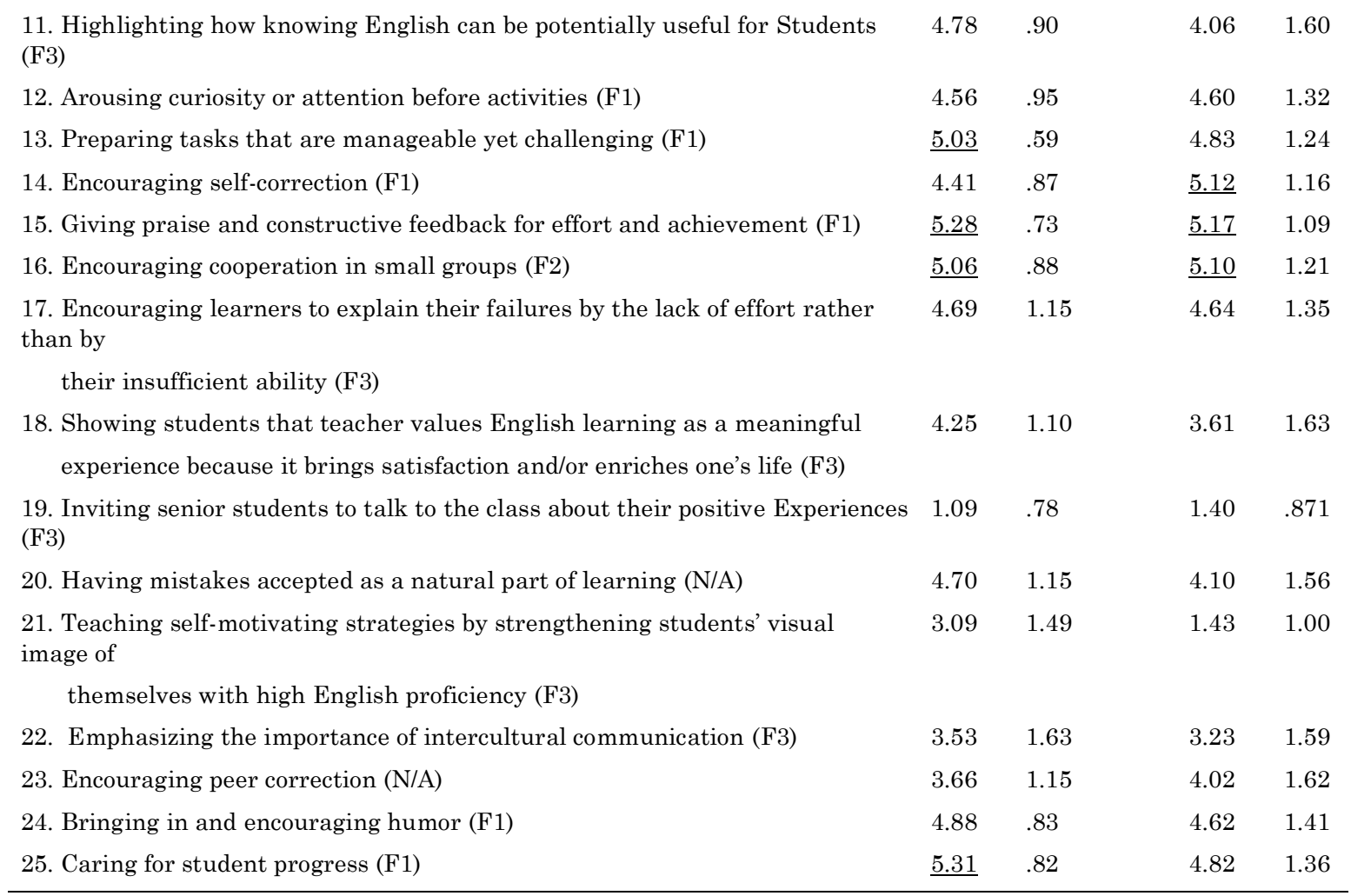

6=almost always; $5=$ often; 4=generally; $3=$ sometimes; $2=$ occasionally; $1=$ never

\subsection{Results of the Exploratory Factor Analysis - TUMSS}

For the exploratory factor analysis on the 25 items of the combined TUMSS data collected from both students and instructors $(N=454)$, maximum likelihood extracting method and the oblique direct oblimin rotation were utilized. Only items with eigenvalues greater than 1 were included in the analysis (Field, 2013); the KaiserMeyer-Olkin (KMO) value was .93, indicating an adequate sample size.

The initial exploratory factor analysis of the TUMSS data revealed four factors with 22 questions loading onto each factor at .3 or higher. Two items (4 and 23) did not load onto any factors, and one item (20) had a value below .3 for factor loadings; therefore, these items were excluded and the EFA was re-run. Cronbach's alpha was improved (.93) after removing these three items. To conclude, the final EFA (KMO = .93) revealed three factors, all of which had eigenvalues over 1 , accounting for $52 \%$ of the total variance. Table 2 below shows the final EFA solution.

Table 2. EFA - Factor Loadings for TUMSS data (N=454) - Teachers' Use of Motivational Strategies Scale

\begin{tabular}{llll}
\multicolumn{4}{c}{ Factors } \\
\hline F1 & F 2 & F3 & h2
\end{tabular}

Factor 1: Proper, supportive, and effective teacher behavior (11 items, CA = .873) 
3. Creating a friendly stress-free learning environment

12. Arousing curiosity or attention before activities $\quad .657$

$.657 \quad .560$

15. Giving praise and constructive feedback for effort/achievement

1. Using ice-breakers at the beginning of each class

24. Bringing in and encouraging humor

14. Encouraging self-correction

5. Giving a genuine meaningful purpose to students to work on activities

Factor 2: Encouraging interaction and cooperation in the L2 class (2 items, CA = .721)

16. Encouraging cooperation in small groups

9. Promoting interaction and cooperation in class

\section{Factor 3: Students' ideal L2 self image (9 items, CA = .712)}

18. Showing students the value of English learning as a meaningful experience

7. Sharing positive views of influential public figures about language learning

8. Emphasizing in class personal interest in learning English

11. Highlighting how knowing English can be potentially useful for students.

10. Promoting exposure to L2 cultural products to familiarize students with the

22. Emphasizing the importance of intercultural communication in the

19. Inviting senior students to talk to our class about their positive experiences.

21. Teaching self-motivating strategies by strengthening students' visual image

17. Encouraging learners to explain their failures by the lack of effort rather

The first factor (F1), Proper, supportive, and effective teacher behavior, explains the highest percentage in variance $(37.26 \%, 11$ items, $\mathrm{CA}=.873)$ The second factor $(\mathrm{F} 2)$ is Encouraging interaction and cooperation in L2 class (two items, $8.50 \%$ of the total variance, $\mathrm{CA}=.721$ ). The third factor (F3) is Students' ideal L2 self image (nine items, $5.76 \%$ of the total variance, $\mathrm{CA}=.712$ ). Unlike the first two factors, all nine items loaded negatively onto F3. The negative direction of factor loadings indicates that participants unanimously believed that the EAP instructors did not frequently use the strategies that loaded onto F3, meaning that the students' ideal L2 selves were not thought to be enhanced by the instructors. In the discussion, a more detailed account of this factor and implications of these results are discussed. Because all the items in F3 negatively loaded, the items were reverse coded before further analysis. The factor averages of both groups are shown in Figure 1 below. 


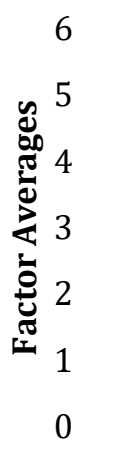

F1

\section{Factor Means Chart by Groups}

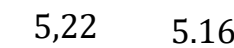

- Instructors

$\backsim$ Students
3,48

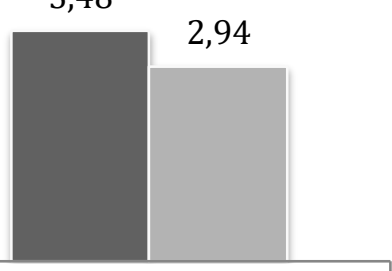

F3

Figure 1. Factor means for both instructor and student groups

The graph above demonstrates that both groups' factor means for F1 and F2 were very similar to each other while groups' means for F3 were different from each other.

\subsection{RQ2-Results of the independent samples $t$-test}

To answer RQ2, independent samples $t$-tests were run on the EFA factor averages to examine if there was a statistically significant difference between the two groups' perceptions of instructors' motivational strategy use. However, when the assumption of homogeneity of variances is violated with the unequal sample sizes of the groups (in this case, instructors' $n=32$ versus students' $n=422$ ), this violation affects the results of the $t$-test (Field, 2013). To resolve this problem and make the data sets more comparable to each other, 32 participants from the student data were randomly selected using random data sampling option, 'select case' function of SPSS (version 23) and the random sample of 32 students' data $(\mathrm{CA}=.854)$ were used to compare means with the 32 instructors' data $(\mathrm{CA}=.839)$ in the independent samples $t$-test ${ }^{\dagger}$ (see Griffiths, Christensen, Jorm, Evans \& Groves, 2004, for another sample of select case use). As the sampling distribution was mainly normal, the random sampling method was used for hypothesis testing (Larson-Hall, 2016; Field 2013).

When assumptions for parametric tests were considered, all four assumptions were met except for one of the three factors (F2) which slightly violated the assumption of normality. Both group distributions for F1 and F3 were sufficiently normal for the $t$ tests according to Kolmogorov-Smirnov, Shapiro-Wilk $(p>.200)$, as well as the graphical summaries of factor averages via $Q-Q$ plots and histograms and skewness value was lower than 1 . Therefore, parametric independent samples $t$-tests were first performed on three factor averages to answer RQ2. Afterwards, nonparametric test was run on the nonparametric variable $\mathrm{F} 2$, of which result was the same as the parametric test. Three independent samples $t$-tests were performed to compare college EFL

\footnotetext{
$\dagger$ In order to test the reliability of the select case function of SPSS, we randomly selected five different data sets of 32 out of 422 students data and ran a one-way ANOVA to examine if there was a statistical difference between the groups. We hypothesized that if the function properly works, there would be no significant difference between the groups. There was no significant effect of group membership on factor averages: $\mathrm{F} 1: F(4,155)=.421, p=.793 ; \mathrm{F} 2: F(4,155)=.678, p=.608$; F3: $F(4,155)=.688, p=.602$. This indicates that the select case function enables completely random selection of smaller cases so we pursued the analysis with confidence.
} 
instructors' motivational strategy use from instructors' and their students' perspectives. Grouping variable was used as the independent and factor averages from the EFA results as the dependent variable with Bonferroni corrections $(p=.017)$ to reduce Type 1 error as multiple t-tests were conducted. Table 3 below shows the results.

Table 3. Results of independent samples t-tests on strategy factor averages

\begin{tabular}{|c|c|c|c|c|c|c|c|c|c|}
\hline & \multicolumn{2}{|c|}{$\begin{array}{l}\text { Instructors } \\
(n=32)\end{array}$} & \multicolumn{2}{|c|}{$\begin{array}{l}\text { Students } \\
(n=32)\end{array}$} & \multirow[t]{2}{*}{$95 \%$ CI } & \multirow[t]{2}{*}{$t$} & \multirow[t]{2}{*}{$d f$} & \multirow[t]{2}{*}{$p$} & \multirow[t]{2}{*}{$\eta 2$} \\
\hline & $\mathrm{M}$ & $\mathrm{SD}$ & $\mathrm{M}$ & SD & & & & & \\
\hline Factor 1 & 4.91 & 0.52 & 4.90 & 0.73 & $-1.17-.81$ & -.054 & 62 & .96 & -.01 \\
\hline Factor 2 & 5.22 & .68 & 5.16 & 1.00 & $-49-.36$ & -.29 & 62 & .772 & .09 \\
\hline Factor 3 & 3.48 & .67 & 2.94 & .66 & $.20-.87$ & 3.2 & 62 & .002 & .81 \\
\hline
\end{tabular}

The results suggest that there was a significant difference for Factor 3 variables, $t(62)=3.2, p=.002<.05 / .017, d=.81$ between instructors $(M=3.48, S D=.67)$ and students $(M=2.94, S D=.66)$ with a large effect size $(d=.81)$. While the instructor group $(n=32)$ believed that they sometimes used the strategies loaded onto F3 $(M=3.48, S D$ $=.67 ; 3=$ sometimes $)$, their students $(n=32 ; M=2.94, S D=.66)$ believed that they were used less frequently and the difference between their perceptions was statistically significant. However, both groups' means for F1 (instructors: $M=4.91, S D=.52$; students: $(M=4.90, S D=.73)$ and F2 (instructors: $M=5.22, S D=.68$; students: $(M=$ 5.16, $S D=1.00$ ) were very similar, indicating similar reports of frequencies for strategies under F1 and F2. The independent samples t-test results demonstrated no significant difference between groups for F1 strategies, $t(62)=-.054, p=.96>.05 / .017$, $d=-.01$ and for Factor 2 strategies $t(62)=-.29, p=.772>.05 / .017, d=.09$.

Even if one variable in a data set is non-parametric, Larson-Hall (2016) recommends non-parametric tests; thus, non-parametric independent-samples $t$-test - MannWhitney U - was performed on F2 averages from both groups. The result of the U test for Factor $2(U=480.500, p>$.663) also showed no statistically significant difference between groups, indicating no group effect on the perceptions. In summary, addressing RQ2, results of the group mean comparisons via the independent samples $t$-tests (and Mann-Whitney U for F2) indicated a statistically significant difference for F3 strategies while showing no group difference for $\mathrm{F} 1$ and F2.

\section{Discussion}

This study fills the research gap in several ways. When focus is on theoretical aspects in SLA, particularly when the framework is relatively new, such as the L2MSS, the connection between research and practice tends to be overlooked. This study is an explicit connection between the theoretical and the practical, thereby providing useful information for those interested in both aspects of language pedagogy. Indeed, recent research seems to indicate that practitioners understand the importance of researchinformed pedagogy (e.g. Sato and Loewen, 2019). In order the do this effectively, a new 
instrument, TUMSS, was created and validated specifically for this study. It is our hope that the TUMSS will be used by other researchers and practitioners in other settings to further bridge the gap between theory and practice.

\subsection{RQ1: Reported Strategy Use and Emergent Factors}

This study examined both student and instructor perceptions of in-class strategy use. For RQ1, the instructors' perceived high frequency usage indicate that the majority of the instructors believe they had already developed a motivational teaching practice. Additionally, results demonstrate that instructors were cognizant of their role as a motivator and facilitator, and that they could increase learner motivation by making learning fun and interesting (i.e. items 24 and 12) and that they enthusiastically created an effective an encouraging learning environment (i.e. items 3, 16, and 13). Considering the high student success at the department in general and the profound support given to instructors' professional development, the effective teaching strategies reported to be frequently used were quiet naturally expected.

A cross-cultural comparison with other studies on motivational strategies demonstrated differences and similarities. For example, one strategy that was not included in other motivational strategies studies in higher education in different EFL contexts (e.g.; Cheng \& Dörnyei, 2007 in Taiwan; Safdari, 2018 in Iran) was reported by the instructors to be the most frequently used strategy 'Promoting interaction and cooperation in classes (Q9)' $(M=5.38 ; S D=.66)$ and confirmed by students' similar mean score $(M=5.27 ; S D=1.09)$. Thus, results indicate that interaction and collaboration in the L2 classroom is the most preferred strategy by both groups in the Turkish EFL context. Additionally, two strategies that were found to be among the most motivating strategies in Hungary (Dörnyei \& Csizér, 1998), Taiwan (Cheng \& Dörnyei, 2007), and the USA (Ruesch, Bown, \& Dewey, 2012) were not reported as frequently used strategies by either group in the current study (items 8 and 18).

In the current study, 'Establishing connections between course content and outside world' and 'Caring for student progress' were reported as two of the frequently used strategies in the context of Turkey, which coincides with the results of Alrabai (2016) and Moskovksy et al. (2013) in Saudi context and Busse and Walter (2013) in English context. Similarly, our findings regarding 'Bringing in humor and fun' into the L2 classroom as an effective motivational strategy in Turkey also aligns with Moskovsky et al. (2013) in the Saudi context. The fact that these kinds of differences and similarities emerged from different L2 contexts emphasize the conclusion that there are some universal motivational strategies and effective L2 teacher behaviors with regard to enhancing learner motivation - which are mostly the same or similar to the strategies loaded onto F1 - while some strategies vary in the efficacy and appropriateness in other contexts due to cultural, contextual, linguistic, and educational circumstances (Cheng \& Dörnyei, 2007; Dörnyei, 2001; Kormos, Kiddle, \& Csizér, 2011). 
Strategies that were reported to be least-frequently or never used were those inspired by the ideal L2 self construct of the L2MSS (Dörnyei, 2005; 2009), with a vivid visualization of a highly proficient L2 learner. Such strategies were items like 'I strengthen my students' visual image of themselves with high language proficiency in English (Q21)', 'I invite senior students to talk to my class about their positive experiences (Q19)', 'I share positive views of influential public figures about L2 learning (Q7)', 'I emphasize in class my own personal interest in learning English (Q8)', and others (e.g.; Q 22, 10, and 18). Their underlying purpose is to increase learners' awareness of the importance of learning an L2 and their own capacity as a language learner, as well as helping them develop a vivid image of themselves as successful L2 learners as a motivating factor. Based on research indicating the effectiveness of visionbuilding strategies in enhancing learner motivation (e.g.; Dörnyei \& Kubanyiova, 2014; Hadfield \& Dörnyei, 2014; Magid \& Chan, 2012), it is important that L2 teachers' motivational strategy use includes such strategies. Our findings about very rare use of L2MSS strategies to enhance learners' mental imagery of ideal L2 selves serve as a call for more research to synthesize L2MSS strategies within the motivational strategy use in the L2 classroom model. We believe motivational strategy questionnaires like TUMSS that consist of these strategies seem to likely to encourage their integration in the L2 classroom.

The final EFA with the three latent variables (factors) presented important points. First, high CA internal reliability measures indicates this questionnaire as reliable for further research. Especially relevant as the questionnaire was created for this study, it can now be used in future studies in a variety of contexts. Second, strategies like "Highlighting how knowing English can be potentially useful for students (Q11)" loaded onto Factor 3, Students' ideal L2 self image, along with other ideal self items (albeit loading negatively), indicating the potential overlap of external (ought-to L2 self) and internal (ideal L2 self) variables (i.e. identified/integrated regulation, Deci \& Ryan, 1985). Deci and Ryan (1985) note that internalization of external motives such as these happen when individuals highly value them and identify themselves with them (see also identified regulation, Noels, 2003). This grouping of items coincides with other research that indicated a potential overlap between internal and external influences (i.e. Thompson \& Erdil-Moody, 2016). Pedagogical implications suggest that instructors can turn, for instance, influential public figures' inspiring views about L2 learning (item 7) or senior students' positive L2 learning experiences (item 19) into motivational strategies to show students 'others' views' about L2 learning to inspire them to put more effort into improving their L2 proficiency. Nevertheless, the negative factor loading for F3 items indicates that these strategies were not used adequately in classes; efforts should be made to remedy this, as a strong ideal self has been shown to relate to successful language learning in a variety of contexts, even when students do not necessarily have strong reasons to use English in their future lives. Nonetheless, in certain contexts, other types of strategies might be perceived to be more useful than enhancing the ideal self, as was the case in the current study. 


\subsection{RQ2: Student/Teacher Group Differences}

For RQ2, independent samples $t$-tests were conducted to examine if there was a significant difference between instructors' and students' perceptions of instructors' motivational strategy use. Results revealed no differences between groups' Factor 1 'Proper, supportive, and effective teacher behavior' and F2 'Promoting interaction and cooperation in the L2 class' data. Both groups agreed that academic English instructors demonstrated motivated and enthusiastic teacher behaviors to create a supportive and effective learning environment and to promote interaction in classes. However, data revealed some intriguing issues with strategies loaded onto F3. The statistically significant difference between groups regarding Factor 3 indicates that instructors and their students had different perceptions of how frequently instructors used strategies to enhance students' ideal L2 self image (or not). Students reported that their instructors do not use a variety of strategies that enhance their ideal selves (F3); the instructor group reported that they sometimes use these strategies. Additionally, the groups were most distinct for items in this category (i.e. items 10, 21, and 7). Notably, five additional strategies were lower for students (items 10,21, 7, 11, 18), increasing the gap between the groups for that latent variable, the variable that is rooted in the latest L2 motivation framework - L2MSS (Dörnyei, 2005; 2009). The differences between groups' perceptions regarding the use of the strategies within F3 suggests a discrepancy between how the teachers perceive enhancing the L2 self via teaching and how the students perceive this type of strategy use in the classroom (e.g. Bernaus \& Gardner, 2008).

Even though the group differences between strategies loaded onto F1 were not statistically significant, two incidents stand out with their relatively bigger group differences: Item 25 with its 5.31 mean for instructors and 4.82 for students, and Item 4 with its 4.30 mean for instructors and only 3.86 for students. For Item 25, both means are still within the frequent use threshold; however, for Item 4, the drop in student data marks the frequency level below the cut-off point (4.00). Findings of a previous study indicate a correlation between students' perceptions of frequency and importance of motivational strategies (Safdari, 2018), a topic for further inquiry. Additionally, student data had larger standard deviations compared to instructors' more clustered responses around the mean. Considering the dynamic nature of L2 motivation and new advances in instructional technology, as well as students' new needs based on the latest global changes and increasing virtual learning platforms, instructors need to adapt their motivational strategies to meet learners' changing needs.

Additionally, there was a great deal of variation in data for item 21 'Teaching selfmotivating strategies by strengthening students' visual image of themselves with high language proficiency in English'. On the one hand, 20\% of the instructors reported that they 'almost never' used this strategy, while another $20 \%$ of the instructors reported that they 'generally' or 'often' use the strategy to strengthen learners' ideal L2 self. On the other hand, about $30 \%$ of the students reported the frequency of this strategy ranging from 'sometimes' to 'generally', while another $30 \%$ reported the same item as 
'almost never' or 'occasionally' used. It is not uncommon that student and instructor perceptions of frequency of strategies that instructors use in classes show similar and also different tendencies (Bernaus \& Gardner, 2008). However, the fluctuating scores for this specific item which is directly relevant to enhancing the ideal L2 self of students rooted in Dörnyei's (2005; 2009) L2MSS theory might indicate either confusion with the concept and/or lack of background knowledge in the theory and how it reconceptualizes L2 learning motivation; alternatively, it could be that other strategies are more relevant in this specific context. Similar discrepancies were observed for the other strategies that were grounded in the L2MSS theory (items $7,17,19$ ). Not only were these strategies excluded from motivational teaching practice of instructors but there was also not much awareness for their significance in enhancing learner motivation. Recently, Dörnyei and Kubanyiova (2014) offered vision-building strategies to help students develop a mental image of themselves as competent L2 speakers. This way, teachers can also increase students' awareness of a need to learn an L2 and strengthen their skills for intercultural communication. It is with no doubt that students nowadays need to be stimulated in the L2 class in a variety of ways due to the inevitable growing need for intercultural communication and global identity in the face of our everchanging world. Vision-building ideal L2 self strategies analyzed above within Factor 3 for EFA rooted in recent research can be incorporated into college EFL instructors' systematic and consistent motivational strategy use, if instructors are able to incorporate them effectively.

Overall, utilizing all of these motivational strategies in the L2 classroom is certainly neither possible nor advisable. The important action for L2 teachers is to be aware of this vast repertoire of motivational strategies at our disposal and to choose those wisely that will apply to their specific teaching contexts and specific learner groups' needs, based on needs analyses and daily observations. Like Dörnyei (2007) always reminds us what matters is quality rather than quantity. For future research, we suggest revisiting the Motivational Teaching Practice in the L2 Classroom model and updating it with strategies that are rooted in the L2 Motivational Self System framework, especially with vision building strategies to strengthen learners' ideal L2 self.

Certainly, this study does not and was not intended to reveal the actual motivational effect that teachers' use of motivational strategies can have on learners in terms of proficiency, which would require an experimental design; however, the results of this study are equally important. To offer a solid motivational teaching model with potentially applicable strategies that can also be adapted to the specific needs and facets of various L2 contexts, extensive amount of data from many various L2 contexts and replications of those studies play a major role in better exploration of teachers' motivational strategy use. We also believe that strategies that work effectively with K12 , middle school, and university students will vary to some extent. With these students specifically, they are taking the EAP classes to then be able to succeed in an Englishmedium university; thus, they should have visions of using English in the future at least through their university education. In other contexts, those taking language classes may be doing so to fill a requirement with no thought for future use of that 
language. Examining instructors' and students' perceived differences about the frequency of strategies also sheds light on their perceived importance of those strategies without openly eliciting their perceptions of importance because their responses, otherwise, could be susceptible to social desirability bias. Instructors might be more inclined to rank strategies based on what they think are effective strategies and should be a part of an effective L2 teachers' daily motivational teaching repertoire. With our study, we attempted to avoid this by asking them a rather factual question like the frequency.

With this questionnaire, the current study fills the research gap in two ways: a) the creation of a motivational strategies questionnaire with a focus on helping students construct L2-related ideal self image, which can be used to develop motivational teaching practice and in action research; b) the contribution to L2 motivation research by offering empirical data for the reliability and validity of the questionnaire TUMSS, allowing for replications in various other L2 contexts. Findings also contribute to research on teachers' use of motivational strategies with data on the most preferred and frequently used teacher strategies to increase learner motivation in this specific EFL context. Despite the growing significance of English in the Turkish EFL context, students' low L2 motivation still is a challenge that EFL teachers face on a daily basis; therefore, pedagogical implications of the findings add to the significance of the study. Finally, this study will contribute to the growing body of research on L2 teacher motivation/behavior as a strong motivator for L2 learners in addition to its data that can be used for cross-cultural comparisons of motivational strategies grounded in the MTP and L2MSS frameworks.

\section{Conclusions}

L2 teachers' use of effective teaching strategies and motivational techniques are certainly not a new phenomenon. Despite the plethora of research on this topic, there has not been an established comprehensive motivational teaching model that could be applied to a variety of L2 contexts and that could guide teachers regarding how to enhance their students' L2 motivation. Motivational Teaching Practice in the L2 Classroom (Dörnyei, 2001) has been the most comprehensive motivational strategy repertoire to date and L2 Motivational Self System (Dörnyei, 2005) has been the most detailed and widely used L2 motivation framework. Guided by these two theories, the current study first examined the overall motivational strategy use of EFL college instructors in the understudied EFL context, Turkey, and then compared instructors and students' perceptions of instructors' use of motivational strategies. Offering a motivational strategy use questionnaire - TUMSS - with exploratory factor loadings and interpretations for the first time in this L2 context and between group differences regarding instructor and student perceptions, this study adds to our understanding of most frequently used motivational strategies in higher education L2 classes. It also allows replications in other L2 contexts and comparisons to see how EFA results, factor loadings, and loading direction, as well as group perceptional differences, vary in other EFL contexts. Due to its global status as the lingua franca, motivational orientations 
to learn English differ and are more multifaceted than learning any other foreign language. Hence, we believe an adaptation of the questionnaire might be necessary before using it for other languages.

Developing one's own systematic motivational teaching requires practice and experimenting with strategies until they find strategies that work with a specific learner group in a specific L2 context/culture and most importantly those which teachers feel comfortable to use. In establishing their MTP, though, we recommend instructors take into consideration students' perceptions of importance and frequency of motivational strategies teachers use in class. Therefore, we would like to remind teachers to be patient, maintain their motivation to develop a consistent and systematic MTP with which they feel comfortable because motivational teaching is the key to effective teaching. With this study, we hope to contribute to research on L2 motivation, foreign/second language teaching and learning, L2 teachers' reflective practice or action research on their own motivational teaching, as well as pre-service L2 teacher education programs.

\section{Acknowledgements}

We are thankful to all the faculty and administration at the university where the study was conducted for their support and welcoming attitude throughout the study. We would also like to thank the students and instructors who graciously participated in this study. Finally, we are grateful to Dr. Nicole Tracy-Ventura and the reviewers for their insightful feedback.

\section{The Research and Publication Ethics Statement}

The Ethics Committee/Board approval for this study was first obtained from METU Research Center for Applied Ethics board on 03/25/2014 and then from the University of South Florida Institutional Review Board (IRB) on 04/24/2014 by No Pro00016576. No ethical considerations were violated in this study.

\section{The Conflict of Interest Statement}

In line with the statement of Committee on Publication Ethics (COPE), we hereby declare that we had no conflicting interests regarding any parties of this study.

\section{References}

Alrabai, F. (2016). The effects of teachers' in-class motivational intervention on learners' EFL achievement. Applied Linguistics 37(3), 307-333. doi:10.1093/applin/amu021.

Arnold, J., Puchta, H., \& Rinvolucri, M. (2007). Imagine that! Mental imagery in the EFL classroom. Cambridge: Cambridge University Press.

Begić, I., \& Mercer, S. (2017). Looking back, looking forward, living in the moment: Understanding the individual temporal perspectives of secondary school EFL learners. Innovation in Language Learning and Teaching, 11(3), 267-281. https://doi.org/10.1080/17501229.2017.1317261

Bernaus, M., \& Gardner, R. C. (2008). Teacher motivation strategies, student perceptions, student motivation, and English achievement. The Modern Language Journal, 92(3), 387-401. doi: 10.1111/j.1540-4781.2008.00753.x. 
Busse, V., \& Walter, C. (2013). Foreign language learning motivation in higher education: A longitudinal study of motivational changes and their causes. The Modern Language Journal, 97(2) 435-456. doi: 10.1111/j.1540-4781.2013.12004.x

Cheng, H. F., \& Dörnyei, Z. (2007). The use of motivational strategies in language instruction: The case of EFL teaching in Taiwan. Innovation in Language Learning and Teaching, 1(1), 153-174. doi: 10.2167/illt048.0.

Csizér, K., \& Kormos, J. (2009). Learning experiences, selves and motivated learning behaviour: A comparative analysis of structural models for Hungarian secondary and university learners of English. In Z. Dörnyei \& E. Ushioda (Eds.), Motivation, language identity and the L2 self (pp. 98-119). Clevedon, UK: Multilingual Matters.

Conway, J. M., \& Huffcutt, A. I. (2003). A review and evaluation of exploratory factor analysis practices in organizational research. Organizational Research Methods, 6(2), 147- 168. https://doi.org/10.1177\%2F1094428103251541

Deci, E., L., \& Ryan, R., M. (1985). Intrinsic motivation and self-determination in human behaviour. New York: Plenum.

Dörnyei, Z. (2001). Motivation strategies in the language classroom. Cambridge, UK: Cambridge University Press.

Dörnyei, Z. (2005). The psychology of the language learner: Individual differences in second language acquisition. Mahwah, New jersey: Lawrence Erlbaum.

Dörnyei, Z. (2007). Creating a motivating classroom environment. In International handbook of English language teaching (pp. 719-731). Springer, Boston, MA.

Dörnyei, Z. (2009). The L2 motivational self system. In Z. Dörnyei \& E. Ushioda (Eds.), Motivation, language identity and the L2 self (pp. 9-42). Clevedon, UK: Multilingual Matters.

Dörnyei, Z. (2019). Towards a better understanding of the L2 Learning Experience, the Cinderella of the L2 Motivational Self System. Studies in Second Language Learning and Teaching, 9(1), 19-30. https://doi.org/10.14746/ssllt.2019.9.1.2

Dörnyei, Z., \& Chan, L. (2013). Motivation and vision: An analysis of future L2 self images, sensory styles, and imagery capacity across two target languages. Language learning, 63(3), 437-462. https://doi.org/10.1111/lang.12005

Dörnyei, Z., \& Csizér, K. (1998). Ten commandments for motivating language learners: Results of an empirical study. Language Teaching Research, 2(3), 203-229. doi: $10.1177 / 136216889800200303$.

Dörnyei, Z., \& Kubanyiova, M. (2014). Motivating learners, motivating teachers. Cambridge: Cambridge University Press.

Dörnyei, Z., \& Taguchi, T. (2010). Questionnaires in second language research: Construction, administration, and processing. (2nd ed.). New York, NY: Routledge.

Dörnyei, Z., \& Ushioda, E. (2011). Teaching and researching motivation (2nd ed.). Harlow, UK: Pearson Education.

Erdil, Z. (2016). Promoting L2 motivation via motivational teaching practice: A Mixedmethods study in the Turkish EFL context. Graduate Theses and Dissertations. http://scholarcommons.usf.edu/etd/6496.

Erten, I. H. (2014). Understanding the reasons behind choosing to teach English as a foreign language. Novitas-ROYAL (Research on Youth and Language), 8(1), 30-44.

Erten, I. H. (2015). Social desirability bias in altruistic motivation for choosing teaching as a career. Journal of Education, 30(1), 77-89.

Field, A. (2013). Discovering statistics using IBM SPSS statistics (4th ed.). London, UK: Sage Publications. 
Gardner, R. C. (1985). Social psychology and second language learning: The role of attitudes and motivation. London, UK: Edward Arnold.

Griffiths, K. M., Christensen, H., Jorm, A. F., Evans, K., \& Groves, C. (2004). Effect of webbased depression literacy and cognitive-behavioural therapy interventions on stigmatising attitudes to depression. The British Journal of Psychiatry, 185(4), 342349. doi: 10.1192/bjp.185.4.342.

Guilloteaux, M. J., \& Dörnyei, Z. (2008). Motivating language learners: A classroom-oriented investigation of the efffects of motivational strategies on student motivation. TESOL Quarterly, 42(1), 55-77. doi: 10.1002/j.1545-7249.2008.tb00207.x.

G*Power: Statistical Power Analyses (n.d.). (Software). Available from http://www.gpower. hhu.de/en.html.

Hadfield, J., \& Dörnyei, Z. (2014). Motivating learning. NY, USA: Routledge.

Henry, A., Korp, H., Sundqvist, P., \& Thorsen, C. (2018). Motivational strategies and the reframing of English: Activity design and challenges for teachers in contexts of extensive extramural encounters. TESOL Quarterly, 52(2), 247-273. https://doi. org/10.1002/tesq.394

Higgins, E. T. (1987). Self-discrepancy: a theory relating self and affect. Psychological Review, 94(3), 319. doi: 10.1037/0033-295X.94.3.319.

Kormos, J., Kiddle, T., \& Csizér, K. (2011). Systems of goals, attitudes, and self-related beliefs in second-language-learning motivation. Applied Linguistics, 32(5), 495-516. doi:10.1093/applin/amr019

Kubanyiova, M. (2006). Developing a motivational teaching practice in EFL teachers in Slovakia: Challenges of promoting teacher change in EFL contexts. TESL-EJ, 10(2), 1-17. Retrieved October 14, from http://tesl-ej.org/ej38/a15.pdf.

Larson-Hall, J. (2016). A guide to doing statistics in second language research using SPSS and R. New York, NY: Routledge.

Loewen, S., \& Gonulal, T. (2015). Exploratory factor analysis and principal components analysis. In L. Plonsky (Ed.), Advancing quantitative methods in second language research (pp. 182-212). New York, NY: Routledge.

Mackay, J. (2019). An ideal second language self intervention: Development of possible selves in an English as a Foreign Language classroom context. System, 81, 50-62. https://doi.org/10.1016/j.system.2019.01.003

Magid, M., \& Chan, L. (2012). Motivating English learners by helping them visualise their Ideal L2 Self: Lessons from two motivational programmes. Innovation in Language Learning and Teaching, 6(2), 113-125. doi: 10.1080/17501229.2011.614693.

Markus, H., \& Nurius, P. (1986). Possible selves. American Psychologist, 41(9), 954. doi: 10.1037/0003-066X.41.9.954.

Moskovsky, C., Alrabai, F., Paolini, S., \& Ratcheva, S. (2013). The effects of teachers' motivational strategies on learners' motivation: A controlled investigation of second language acquisition. Language Learning, 63(1), 34-62. doi: 10.1111/j.14679922.2012.00717.x.

Noels, K. A. (2003). Learning Spanish as a second language: Learners' orientations and perceptions of their teachers' communication style. Language Learning, 53(S1), 97 136. doi: 10.1111/1467-9922.53225.

Papi, M., \& Abdollahzadeh, E. (2012). Teacher motivational practice, student motivation, and possible L2 selves: An examination in the Iranian EFL context. Language Learning, 62(2), 571-594. doi:10.1111/j.1467-9922.2011.00632.x

Plonsky, L., \& Oswald, F. L. (2014). How big is 'big'? Interpreting effect sizes in L2 research. Language Learning, 64(4), 878-912. doi:10.1111/lang.12079. 
Raviv, A., Raviv, A., \& Reisel, E. (1990). Teachers and students: Two different perspectives?! Measuring social climate in the classroom. American Educational Research Journal, 27,(1), 141-157. https://doi.org/10.3102\%2F00028312027001141

Ruesch, A., Bown, J., \& Dewey, D.P. (2012). Student and teacher perceptions of motivational strategies in the foreign language classroom. Innovation in Language Learning and Teaching 6(1), 15-27. https://doi.org/10.1080/17501229.2011.562510

Safdari, S. (2018). Iranian EFL learners' perception of the importance and frequency of teachers' motivational strategies. Eurasian Journal of Applied Linguistics, 4(1), 1725. doi: 10.32601/ejal.460625

Sato, M., \& Loewen, S. (2019). Do teachers care about research? The research-pedagogy dialogue. ELT Journal, 73(1), 1-10. https://doi.org/10.1093/elt/ccy048

Schulz, R. A. (2001). Cultural differences in student and teacher perceptions concerning the role of grammar instruction and corrective feedback: USA-Colombia. Modern Language Journal, 85(2), 244-258. https://doi.org/10.1111/0026-7902.00107

Thompson, S. A. (2017). Don't tell me what to do! The anti-ought-to self and language learning motivation. System, 67, 38-49.

Thompson, S. A., \& Erdil-Moody, Z. (2016). Operationalizing multilingualism: Language learning motivation in Turkey. International Journal of Bilingual Education and Bilingualism, 19(3), 314-331. doi: 10.1080/13670050.2014.985631.

Thompson, S. A., \& Lee, J. (2013). Anxiety and EFL: Does multilingualism matter? International Journal of Bilingual Education and Bilingualism 16(6), 730-749. doi:10.1080/13670050.2012.713322 .

Thompson, S. A., \& Sylven, L. K. (2015). Does English make you nervous? Anxiety profiles for CLIL and non-CLIL students in Sweden. Journal of Applied Language Studies, 9(2), 123. https://doi.org/10.17011/apples/urn.201512093950

\section{Appendix A. Teachers' Use of Motivational Strategies Scale (TUMSS) - Teacher Version}

(Adapted from the Motivational Teaching Practice in the L2 classroom \& L2MSS Frameworks (Dörnyei, 2001; 2005)

The following questionnaire is a list of motivational strategies. Please put a tick in the box that most accurately describes how frequently you use each strategy (please do not feel that you are expected to use all/any of them). 1 (almost never); 2 (occasionally); 3 (sometimes); 4 (generally); 5 (often); 6 (almost always)

\begin{tabular}{|c|c|c|c|c|c|c|c|}
\hline & How often do you use these strategies? & 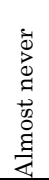 & 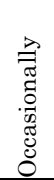 & 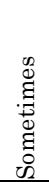 & 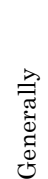 & 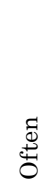 & 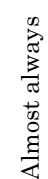 \\
\hline 1 & I use ice-breakers at the beginning of each class & & & & & & \\
\hline 2 & I clearly state lesson objectives at the beginning of each class & & & & & & \\
\hline 3 & I create a friendly stress-free learning environment & & & & & & \\
\hline 4 & I encourage risk-taking in my classes. & & & & & & \\
\hline 5 & I give a genuine meaningful purpose to students to work on activities & & & & & & \\
\hline 6 & I establish connections between my course content and outside world & & & & & & \\
\hline 7 & I share positive views of influential public figures about language learning & & & & & & \\
\hline 8 & I emphasize in class my own personal interest in learning English & & & & & & \\
\hline 9 & I promote interaction and cooperation in my classes & & & & & & \\
\hline 10 & I promote exposure to L2 cultural products to familiarize students with L2 culture. & & & & & & \\
\hline
\end{tabular}




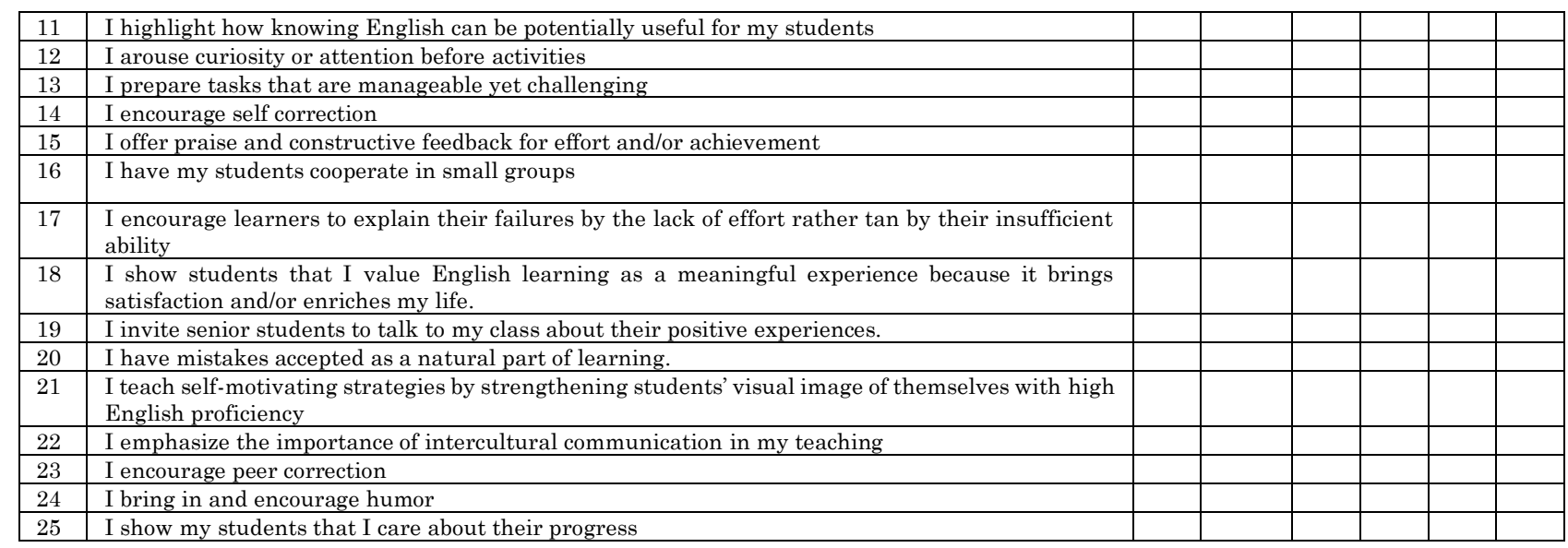

\section{Teachers' Use of Motivational Strategies Scale (TUMSS) - Student Version}

(Adapted from the Motivational Teaching Practice in the L2 classroom \& L2MSS Frameworks (Dörnyei, 2001; 2005)

“Türkçeyi ana dili olarak kullanan öğrencilerin İngilizce öğrenimi motivasyonlarini etkileyen faktörler konulu araştırma projesine katılmayı kabul ettiğiniz için teşekkür ederiz. Yanıtlarınız yabancı dil öğrenimi ve öğretilmesi sürecinin aşamalarını daha ayrıntılı anlamamıza yardımcı olacaktır. Bu anketi tamamlamanız yaklaşık olarak dörtrt - beș dakikanızı alacaktır. Bu anketi tamamlamak zorunlu değilsiniz ama eğer tamamlarsaniz, yanıtlarınız gizli tutulacaktır. Konu hakkında daha fazla bilgi edinmek ve sorularınız için zerdil@ mail.usf.edu adresinden Zeynep Erdil-Moody ile iletişime geçebilirsiniz. Aşağıda yabancı dil öğretiminde kullanilan bazı stratejiler verilmistir. Lütfen Akademik İngilizce sınıfi öğretmeninizin bu stratejileri ne sıklıkla kullandığını uygun kutuları işaretleyerek belirtiniz. Örneğin verilen, öğretmeninizin hic kullanmadigi bir strateji ise "almost never", her zaman kullandigi bir strateji ise "almost always" kutusunu işaretleyebilirsiniz.

The following questionnaire is a list of motivational strategies that L2 teachers use grounded in their motivational teaching practice. Please put a tick in the box that most accurately describes your Academic English instructor's use of each strategy (please do not feel that you are expected tick all/any boxes). 6 (almost always) nerdeyse her zaman; 5 (often) s1k s1k; 4 (generally) genellikle; 3 (sometimes) bazen; 2 (occasionally) arada bir; and 1(almost never) neredeyse hiç bir zaman.

\begin{tabular}{|c|c|c|c|c|c|c|c|}
\hline & $\begin{array}{l}\text { How often does your ENG instructor use these strategies? } \\
\text { Question: This semester, my foreign language instructor/ Bu dönem Ingilizce öğretmenim }\end{array}$ & 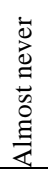 & 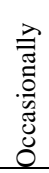 & $\stackrel{\mathscr{Q}}{\mathscr{\Xi}}$ & 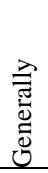 & $\underbrace{ \pm}_{0}$ & 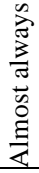 \\
\hline 1 & $\begin{array}{l}\text { uses ice-breakers at the beginning of each class } \\
\text { derse, bizi rahatlaticl kişisel sohbetlerle ya da interaktif, tiyatral veya iletișimsel etkinlikler ile başlar }\end{array}$ & & & & & & \\
\hline 2 & $\begin{array}{l}\text { clearly states lesson objectives at the beginning of each class } \\
\text { her dersin başında ders amaçlarını açık bir şekilde bizimle paylaşır }\end{array}$ & & & & & & \\
\hline 3 & $\begin{array}{l}\text { creates a friendly stress-free learning environment } \\
\text { bizim için gergin olmayan stresten uzak bir sinıf ortamı sağlar }\end{array}$ & & & & & & \\
\hline 4 & $\begin{array}{l}\text { Encourages risk-taking in our classes } \\
\text { derslerimizde risk almayı teşvik eder }\end{array}$ & & & & & & \\
\hline 5 & $\begin{array}{l}\text { gives us a genuine meaningful purpose to work on activities } \\
\text { sinıf aktivitelerine katılmamız için bizi motive edecek gerçekçi sebepler verir }\end{array}$ & & & & & & \\
\hline 6 & $\begin{array}{l}\text { establishes connections between her/his course content and outside world } \\
\text { kendi ders içeriğini sınıf dışında ki hayatımıza bağlantılar kurarak işler }\end{array}$ & & & & & & \\
\hline 7 & $\begin{array}{l}\text { shares positive views of influential public figures about language learning } \\
\text { halk arasında etkili ve sevilen kişilerin dil ögrenimi hakkındaki olumlu yorumlarını bizimle paylaşır }\end{array}$ & & & & & & \\
\hline
\end{tabular}




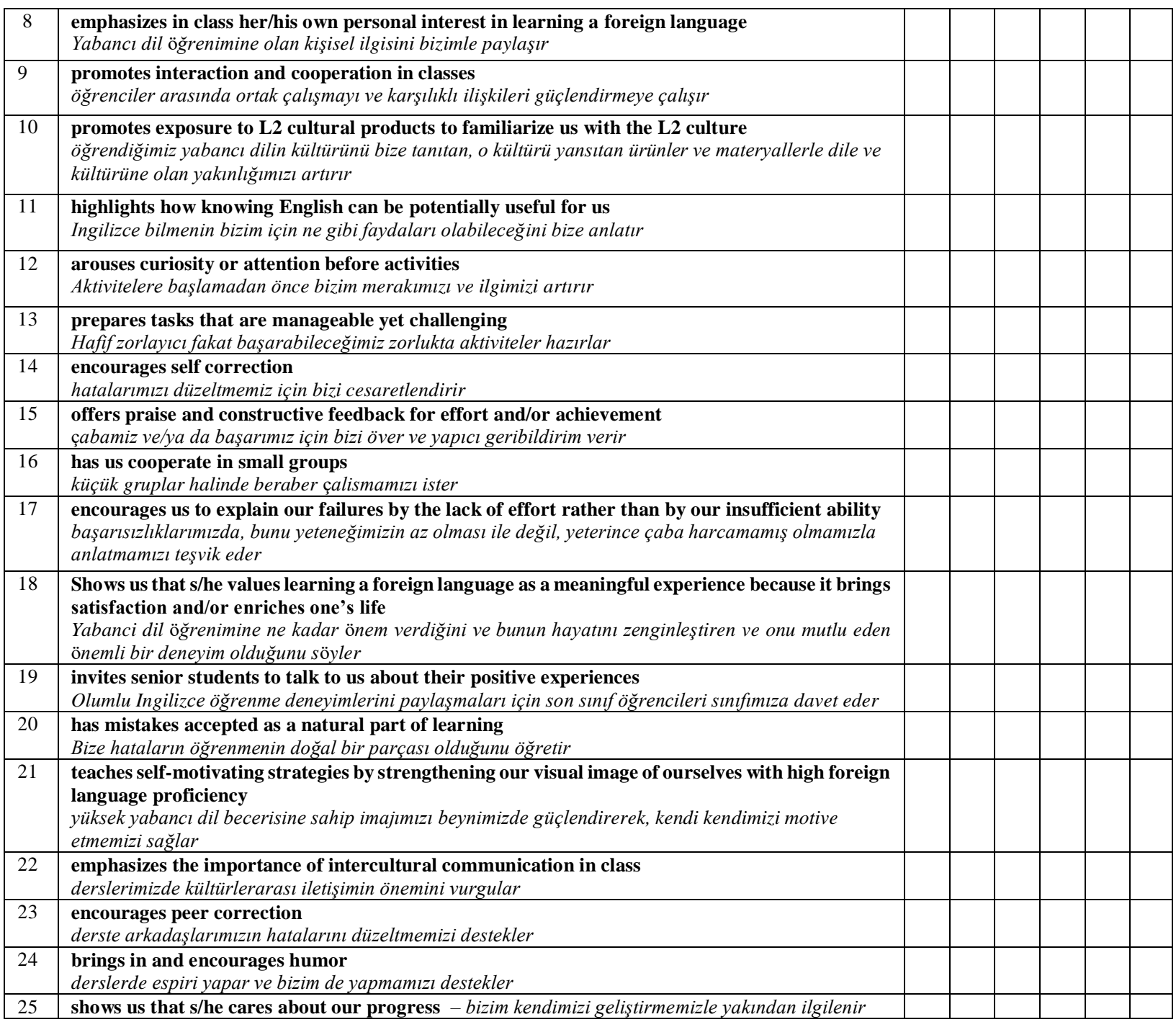

\section{Copyrights}

Copyright for this article is retained by the author(s), with first publication rights granted to the Journal.

This is an open-access article distributed under the terms and conditions of the Creative Commons Attribution license (CC BY-NC-ND) (http://creativecommons.org/licenses/by-nc-nd/4.0/). 